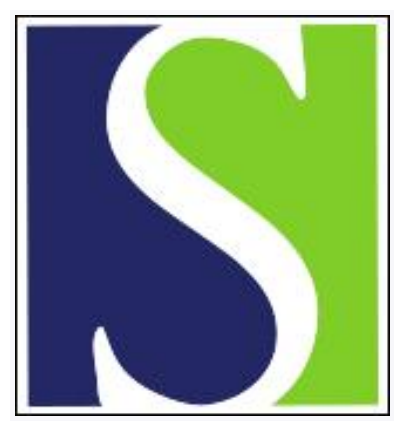

Scand J Work Environ Health 2010;36(3):258-265

https://doi.org/10.5271/sjweh.2877

Published online: 26 Nov 2009, Issue date: 01 May 2010

\title{
Fall prevention among apprentice carpenters
}

by Kaskutas V, Dale AM, Lipscomb H, Gaal J, Fuchs M, Evanoff B

Affiliation: Washington University School of Medicine, Program in Occupational Therapy, 4444 Forest Park Avenue, Saint Louis, MO 63110. kaskutasv@wustl.edu

The following article refers to this text: 2011;37(6):525-532

Key terms: apprentice; apprentice carpenter; carpenter; construction; construction safety; fall; fall prevention; injury; injury prevention; ladder; prevention; safety; safety and health

This article in PubMed: www.ncbi.nlm.nih.gov/pubmed/19953214 


\title{
Fall prevention among apprentice carpenters
}

\author{
by Vicki Kaskutas, OTD, ${ }^{1}$ Ann Marie Dale, PhD, ${ }^{2}$ Hester Lipscomb, PhD, ${ }^{3}$ John Gaal, EdD, ${ }^{4}$ Mark Fuchs, \\ $B S c,{ }^{5}$ Bradley Evanoff, $M D^{2}$
}

\author{
Kaskutas V, Dale AM, Lipscomb H, Gaal J, Fuchs M, Evanoff B. Fall prevention among apprentice carpenters. Scand \\ J Work Environ Health. 2010;36(3):258-265.
}

\begin{abstract}
Objective Falls from heights are a leading cause of mortality and morbidity in the construction industry, especially among inexperienced workers. We surveyed apprentice carpenters to identify individual and organizational factors associated with falls from heights.
\end{abstract}

Methods We developed a 72-item survey on fall prevention with multiple domains including fall experience, fall-prevention knowledge, risk perceptions, confidence in ability to prevent falls, training experience, and perceptions of the safety climate and crew safety behaviors. We administered the questionnaire to apprentice carpenters in this cross-sectional study.

Results Of the 1025 respondents, $51 \%$ knew someone who had fallen from a height at work and $16 \%$ had personally fallen in the past year, with ladders accounting for most of the falls. Despite participation in schoolbased and on-the-job training, fall-prevention knowledge was poor. Ladders were perceived as low risk and ladder training was rare. Apprentices reported high levels of unsafe, fall-related behaviors on their work crews. Apprentices in residential construction were more likely to fall than those in commercial construction, as were apprentices working on crews with fewer senior carpenters to provide mentorship, and those reporting more unsafe behaviors among fellow workers.

Conclusions Despite participation in a formal apprenticeship program, many apprentices work at heights without adequate preparation and subsequently experience falls. Apprenticeship programs can improve the timing and content of fall-prevention training. This study suggests that organizational changes in building practices, mentorship, and safety practices are also necessary to decrease worker falls from heights.

Key terms construction; construction safety; injury prevention; ladder; safety and health.

In 2007, the US construction industry experienced more fatalities than any other industry (1), with falls accounting for $37 \%$ of these fatalities (2). Falls accounted for an even larger proportion of the fatalities in residential construction, causing $42 \%$ of fatalities in new single-family home construction, and 55\% in residential framing (2). Deaths due to falls in construction have risen in the past decade contrary to national trends of declining mortality from other occupational fatalities $(3,4)$.

In a three-year active surveillance project with over 5000 unionized residential carpenters, falls from height accounted for $20 \%$ of all the US Occupational Safety and Health Administration's (OSHA's) recordable injuries
(4). These falls occurred most often from ladders, scaffolding, roofs, unsecured surfaces, and unprotected openings (5). Fall protection strategies mandated by OSHA construction standards (6) and alternative strategies described in the OSHA residential guidelines (7), (such as guardrails, toe boards, tying off to appropriate anchors, and guarding openings) would have prevented many of these falls; unfortunately, these practices were not the norm at these sites (5). Many of these non-fatal events (5) bear striking similarity to the fatal falls described in the fatality assessment and control evaluation program at the US National Institute of Occupational Safety and Health (8).

1 Program in Occupational Therapy, Washington University School of Medicine, St Louis, MO, United States.

2 Division of General Medical Sciences, Department of Internal Medicine, Washington University School of Medicine, St Louis, MO, United States.

3 Division of Occupational and Environmental Medicine, Duke University, Durham, NC, United States.

4 Carpenters' District Council, St Louis, MO, United States.

5 Carpenters' Joint Apprenticeship Program, St Louis, MO, United States.

Correspondence: V Kaskutas, Washington University School of Medicine, Program in Occupational Therapy, Campus Box 8505, 4444 Forest Park Avenue, Saint Louis, MO 63110, USA. [E-mail: kaskutasv@wustl.edu] 
Construction worker safety when working on elevated surfaces depends upon a multitude of factors, including: (i) individual or intrinsic factors, such as physical agility, vigilance, knowledge, attitudes, and beliefs; (ii) organizational factors at the contractor level, such as equipment, safety climate, access, and management practices; and (iii) societal factors, such as federal inspections, safety standards, and economic conditions and resulting pressures. Individual skills necessary to succeed in construction are developed through school-based instruction and on-the-job mentorship. Organizational factors [such as the size of the firm (9) and observed safety environment or climate (5, 10)] influence worker safety and vary greatly among contracting companies. Societal factors drive the pace of the construction trade and strongly affect both the organization and the individual.

The goals of this study were to describe the distribution of individual and organizational factors related to fall prevention in a large cross-sectional study of apprentice carpenters and examine associations between these factors and reported falls from height. Our study focused on residential construction workers, a high-risk population that has not been widely studied. The results from this project will help researchers, union leaders, apprenticeship trainers, and residential contractors identify and design interventions to improve fall prevention in the residential construction industry at both the individual level, through apprenticeship training experiences, and at the organizational level, through worksite assessment, mentorship, supervision, and the modification of building practices.

\section{Methods}

\section{Population}

The study population for our survey comprised apprentice carpenters who were attending regularly scheduled training at the Carpenters' Joint Apprenticeship Program (CJAP) in St Louis, Missouri, USA during a six-month period between December 2005 and May 2006. We initially sampled all apprentices to reach a goal of covering 200 apprentices in each year of the four-year, union-based training program; then we oversampled second- and third-year apprentices to provide a comparison group for future intervention studies. The CJAP is supported by the Carpenters' District Council of Greater St Louis and Vicinity and the Home Builder's Association of Greater St Louis. At the time of the study, there were 2400 apprentice carpenters in the four-year apprenticeship program. Of these, $90 \%$ performed residential construction.

\section{Questionnaire development and administration}

We identified domains of interest relevant to fall prevention by reviewing US construction safety standards $(6,7,11-13)$, fall statistics, and literature exploring fall causation, consultation with subject matter experts, and focus groups with apprentice carpenters at various stages of their training (14). We reviewed existing measurement tools in the process of constructing questionnaire items, including some that were specific to construction $(4,15-$ 18 ) and others used in different occupational groups that explored relevant concepts (19). We administered a preliminary version of the questionnaire to the CJAP trainers and several apprentices, facilitating feedback in focus group format. Our final questionnaire had 72 items with 11 domains including: demographic data, employment data, fall history, task performance and equipment use history and training, risk perceptions, knowledge, confidence, work-crew behaviors, workplace safety climate, barriers to fall protection, and training effectiveness.

The employment data section identified the amount of time worked in residential construction in the last year, employer size, and the average number of journeymen (skilled craftsmen) and apprentices in a work crew. In exploring fall history, we defined a fall from height as "falling from one height to another, like falling from a ladder or down several steps, but not a fall to the floor on which you are standing". If apprentices reported a fall from a height in the past year, they identified: (i) the type of surface from which they fell, (ii) the distance fallen, (iii) medical treatment and work status after the fall, (iv) factors that contributed to the fall, and (v) what could be done to prevent others from experiencing this type of fall.

Apprentices reported if they received school-based and on-the-job training prior to performing 11 designated work tasks or using specific equipment. Eight multiple-choice questions assessed fall-prevention knowledge of OSHA construction standards. Apprentices rated the degree of fall risk for 12 common work tasks and rated confidence in their ability to use safety equipment ( 2 items) and prevent falls ( 2 items). The frequency of 5 crew behaviors while working at heights was rated on a 5 point scale. Also using a 5-point scale, 5 items measured the apprentices' perceptions of their workplace safety climate. These items represented various levels of organizational factors described by Bolman \& Deal (20).

Instructors distributed the survey and informed consent forms to apprentices attending regularly scheduled school-based training at CJAP and explained the project and its voluntary nature. The apprentices placed all surveys, completed or not, in sealed envelopes and deposited them in a box in the classroom, from which a university researcher retrieved them. The Institutional Review Board at Washington University approved all procedures. 
The questionnaire was distributed to 1037 apprentices in all stages of training, of which 1025 responded (98.9\% response rate). Respondents comprised $43 \%$ of the 2400 apprentices in the Carpenters' District Council at the time. The mean age was 26 years [standard deviation (SD) 5.8, range 18-49]. The majority of apprentices were white males. Twenty-one percent $(21 \%)$ of respondents were first-year apprentices, 30\% second-year, 31\% third-year, and 19\% fourth-year apprentices. The majority of the apprentice respondents framed single-family homes for large-sized contractors.

\section{Data management and analysis}

We generated initial descriptive statistics for all variables including frequencies of categorical responses and distributions of continuous variables. Employer size was categorized into small ( $<25$ carpenters), medium (26-75 carpenters), and large ( $>75$ carpenters). We calculated the percentage of knowledge questions answered correctly for each participant. In order to calculate the scores for the safety climate, crew behavior, risk perception, and confidence domains, we added the score for each item within the domain (item scores ranged from 1-4 or 5), equally weighting each item, and divided by the number of items in the domain. For domains with missing items, we computed the mean score for that domain and imputed this mean value for the missing value(s) if at least $75 \%$ of the items were completed. Scale reliability was assessed using Cronbach's alpha to assess the internal consistency of items within the scales in our apprentice sample.

We expected that falls would be more common: (i) among apprentices with less carpentry experience, (ii) among residential compared to commercial carpenters, (iii) at sites where the ratio of apprentices to journeymen was high, (iii) and at sites with high rates of unsafe worker behavior when working at heights. Since our scales were internally consistent based on Cronbach's alpha (0.92 risk perception, 0.78 safety climate, 0.67 confidence, and 0.60 crew behavior), we used domain scores to combine individual variables for analysis. We explored the relationships between fall experience and the individual and organizational domains of the survey using standard parametric and non-parametric statistics. We computed crude odds ratios for each domain/variable and for the employer size categories for all falls from heights and ladder falls, and entered all variables/scales into multivariate logistic regression models using forward stepwise and backward selection methods. Variables with P-values $\leq 0.05$ were considered to be statistically significant. We assessed the model fit using the Hosmer \& Lemeshow goodness-of-fit test. Analyses were pre-specified and performed using SAS version 9.2 (SAS Institute, Cary, NC, USA).

\section{Results}

Over half of the apprentices reported knowing a colleague who experienced a serious work-related fall from a height. In the past year, $16 \%$ had personally fallen from a height. Of those who fell $(\mathrm{N}=164), 17(10.4 \%)$ lost work time, $9(5.6 \%)$ returned to restricted work, 26 (15.9\%) received medical care, and $13(7.9 \%)$ received prescription medication. The average distance fallen was 3 meters, with a range from 0.6-9 meters. The largest percentage $(30 \%)$ of the falls occurred from ladders (figure 1). Loss of balance, slipping/tripping, and weather conditions were the most common contributing factors (figure 2). When asked what could be done to prevent someone else from experiencing the same type of fall, respondents mentioned two organizational factors (increased availability of proper working equipment and avoid working in bad weather) and one individual factor (working extra carefully). Other factors could be attributed to both the organizational and individual level, such as proper installation of equipment, slowing the work pace, and consistently using fall-protection methods.

We asked about common work tasks and equipment use related to falls or fall prevention. While most apprentices were trained prior to performing these tasks, their training was not aligned with the required work tasks (table 1). Use of step and extension ladders were the two most common work tasks reported $(97 \%$ and $96 \%$, respectively) yet the least common tasks in which apprentices were trained prior to performance on the job ( $53 \%$ and $56 \%$, respectively). Only two thirds of apprentices reported that they were trained before performing other common tasks at a height, including roof sheathing and setting trusses, joists, and outside walls. Conversely, $87 \%$ of apprentices were trained to use personal fall arrest systems (a body harness and lanyard used to arrest

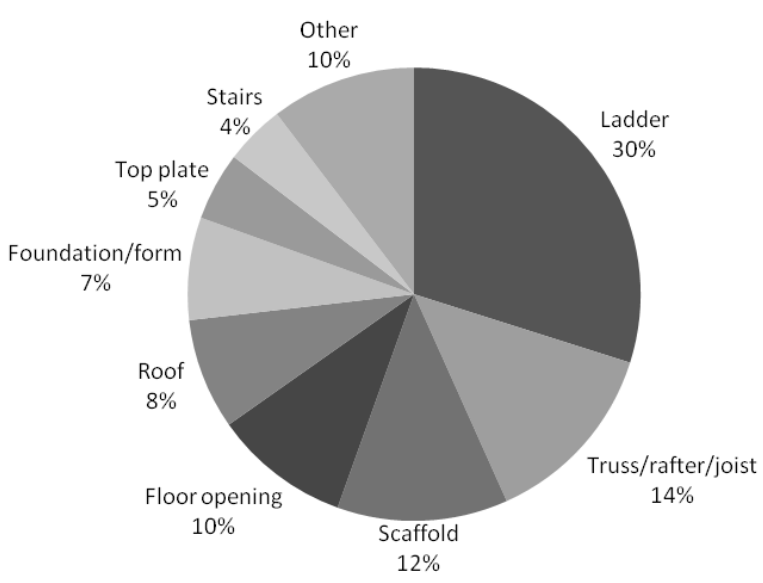

Figure 1. Surfaces apprentices fell from or through ( $N=164$ apprentices who fell from a height). 
a fall), although apprentices reported that these systems were commonly used at only $13 \%$ of worksites.

Respondents to the questionnaire had a mean knowledge score (percentage correct) of 56\%, ranging from $72 \%$ for the height requirements for fall protection to $35 \%$ for the size of a hole in the floor that must be covered. Most apprentices believed the size of a floor opening that required covering was 12 inches $(30 \mathrm{~cm})$ or larger in diameter, rather than 2 inches $(4.4 \mathrm{~cm})$ as defined by OSHA. Approximately half of the apprentices knew that standing on the external top plate (top of the outside house wall) was never permitted, although $27 \%$ believed it was allowed to install roof trusses or floor joists or lay out rafters. Correct extension ladder setting methods were known by less than two thirds of apprentices surveyed.

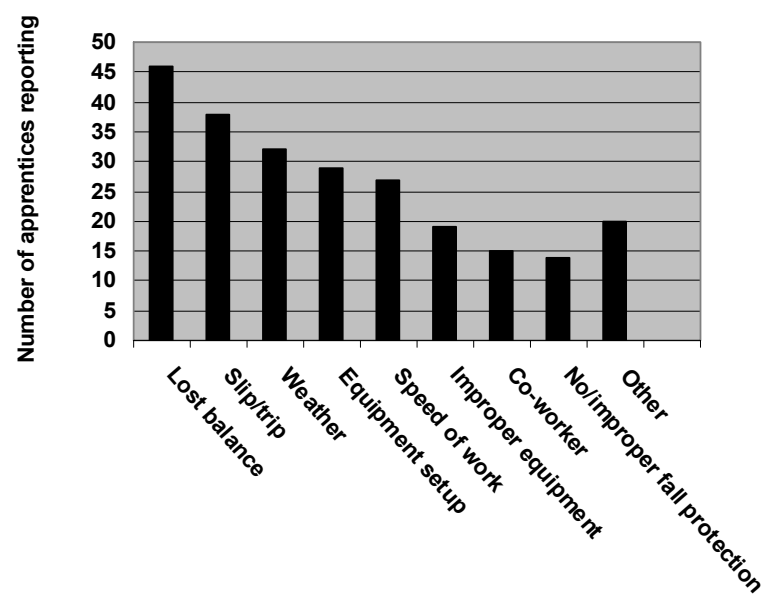

Figure 2. Factors reported to contribute to falls from height ( $N=164$ apprentice falls).

Table 1. Apprentices who reported performing tasks on the job and percent who received training prior to performing task on the job.

\begin{tabular}{lcc}
\hline Task & $\begin{array}{c}\text { Performed } \\
\text { task on the } \\
\text { job } \\
(\%)\end{array}$ & $\begin{array}{c}\text { Trained } \\
\text { prior to task } \\
\text { performance } \\
(\%)\end{array}$ \\
\hline Use personal fall arrest & 81.4 & 87.1 \\
Use pump jack scaffold & 66.2 & 76.4 \\
Use ladder jack scaffold & 78.9 & 68.0 \\
Work near unprotected openings/edges & 82.1 & 67.7 \\
Set outside walls & 86.5 & 67.6 \\
Set trusses & 85.0 & 65.8 \\
Set joists & 84.3 & 65.6 \\
Sheath roof & 78.8 & 61.8 \\
Use extension ladder & 96.1 & 56.5 \\
Use step ladder & 96.7 & 53.0 \\
\hline
\end{tabular}

Respondents rated step ladders as the work task or equipment which posed the least risk of causing a fall, while truss setting and working on the top plate were rated as having a high fall risk (table 2). Confidence ratings were high among apprentices surveyed, even among those who reported falling in the previous year; most believed they could use the personal fall arrest system correctly and prevent a fall from heights.

When asked about work-crew behaviors, apprentices reported that they always or often observed crew members performing unsafe acts, such as standing on the exterior top plate (40\%), walking on floor joists (36\%), and using unopened step-ladders leaned against a wall (39\%). Forty eight percent $(48 \%)$ of the apprentices reported that personal fall arrest systems were not used at the worksite; only $13 \%$ of those surveyed responded that they were used often or always. However, more siding installers and roofers reported using the personal fall arrest systems often or always $(28 \%$ and $22 \%$, respectively). Despite OSHA's residential guidelines' requirement for controlled access zones to be monitored by a designated worker or foreman, $21 \%$ of apprentices reported that unprotected floor openings were never monitored.

Regarding the workplace safety climate, most respondents agreed that (i) journeymen teach them how to do the job safely, (ii) safety is a priority with management/foremen, (iii) there is adequate time to work safely and meet production deadlines, and (iv) they feel free to report safety violations. However, $16 \%$ reported that they had been asked to "sign off" on safety training that they did not attend. Respondents reported a mean number of four members in each work crew, including two journeymen and two apprentices, resulting in a mean journeyman to apprentice ratio of $1: 1$.

Table 2. Apprentices' perception of fall risk for different work tasks. Ratings on $1-10$ Scale (1=no risk, 10=extreme risk). [SD = standard deviation; 1 inch $=2.54 \mathrm{~cm}$ ]

\begin{tabular}{lll}
\hline & Mean & SD \\
\hline Work on roof $>9$ inch 12 pitch & 7.2 & 2.5 \\
Set trusses & 6.4 & 2.5 \\
Work on top plate & 6.3 & 2.7 \\
Work at unprotected opening/edge & 5.6 & 2.7 \\
Work on roof between 5-9 inch 12 pitch & 5.4 & 2.5 \\
Frame roof structure & 5.2 & 2.6 \\
Work near unprotected stair opening & 5.2 & 2.8 \\
Use extension ladder & 4.8 & 2.4 \\
Use scaffolding & 4.3 & 2.4 \\
Work near unprotected window & 3.9 & 2.7 \\
Work on roof <4 inch 12 pitch & 3.2 & 2.3 \\
Use step ladder & 3.2 & 2.2 \\
\hline
\end{tabular}




\section{Factors associated with crew behaviors and falls}

Safer work climate ratings demonstrated a moderate correlation (0.43) with safer crew behavior ratings (table 3 ). Variables which demonstrated weak correlations with safer crew behaviors included: (i) receiving training in a greater number of tasks, (ii) higher confidence ratings, and (iii) working for a large-sized employer (versus a small- or medium-sized one). Weak, negative correlations were noted between higher percentage of apprentices at the worksite, higher risk perception ratings, and a greater amount of residential work (versus commercial). Knowledge and age were not correlated with crew behaviors.

Crude odds ratios for all falls from a height and ladders are described in table 4. Apprentices working in residential construction experienced more falls than those in commercial construction $(17.7 \%$ versus $9.3 \%)$, and apprentices with $<1$ year in the carpentry trade experienced more falls than those with $>5$ years experience $(18 \%$ versus $6.8 \%)$. Apprentices working on crews with safer work behaviors and climates were less likely to experience falls, as were those on crews with fewer apprentices. Knowledge was not associated with falls from heights. There was no difference in the number of falls at contractors of different size.

Among apprentices working in residential construction, the strongest independent risk factor predicting falls was having $<1$ year of work experience (table 5). Apprentices who performed a wider variety of work tasks were $52 \%$ more likely to experience ladder falls. For every $10 \%$ increase in the percentage of apprentices at the

Table 3. Scale and item correlations to safer crew behavior score. (OSHA = Occupational Safety and Health Administration)

\begin{tabular}{|c|c|c|c|}
\hline Variable/scale $^{\text {a }}$ & $\begin{array}{l}\text { Correlation } \\
\text { coefficient }\end{array}$ & $\begin{array}{l}\text { Median } \\
\text { crew } \\
\text { behavior } \\
\text { score }^{b}\end{array}$ & $\begin{array}{c}\text { P- } \\
\text { value }\end{array}$ \\
\hline Safer work climate score & 0.43 & . & $<0.0001$ \\
\hline $\begin{array}{l}\text { Percent of task trained prior } \\
\text { to performance }\end{array}$ & 0.22 & - & $<0.0001$ \\
\hline Higher confidence levels & 0.23 & . & $<0.0001$ \\
\hline Percent apprentices on crew & -0.10 & . & 0.003 \\
\hline Higher risk perception score & -0.11 & - & 0.0002 \\
\hline Greater residential work in past year & -0.12 & - & 0.004 \\
\hline Higher OSHA knowledge score & 0.05 & . & 0.146 \\
\hline Age in years & 0.001 & - & 0.976 \\
\hline \multicolumn{4}{|l|}{ Employer size ${ }^{c}$} \\
\hline Small (<25 carpenters) & . & 2.3 & $<0.0001$ \\
\hline Medium (26-75 carpenters) & $\cdot$ & 2.3 & \\
\hline Large (>75 carpenters) & . & 2.7 & \\
\hline
\end{tabular}

a Spearman's rho.

b Higher scores denote safer behaviors on a 1-5 scale.

c Wilcoxon non-parametric test. worksite, there was a $27 \%$ increase in ladder falls. Safer crew behaviors were protective, with a 1-point improvement in crew behavior resulting in a $10 \%$ decreased likelihood of all falls from a height and ladder falls.

\section{Discussion}

We surveyed 1025 apprentice carpenters to measure their fall-prevention knowledge, beliefs, fall experiences and views on crew behaviors, safety climate, and other factors associated with falls from a height. Despite participation in a formal apprenticeship program that

Table 4. Associations between falls from heights for all apprentices surveyed (logistic regression). Only variables/scales significant at $\mathrm{P} \leq 0.05$ are reported. ( $\mathrm{OR}=$ odds ratio, $95 \% \mathrm{Cl}=95 \%$ confidence interval)

\begin{tabular}{|c|c|c|c|c|}
\hline \multirow[t]{2}{*}{ Variables } & \multicolumn{2}{|c|}{$\begin{array}{l}\text { All falls } \\
(N=938)\end{array}$} & \multicolumn{2}{|c|}{$\begin{array}{l}\text { Ladder falls a } \\
\qquad(\mathrm{N}=871)\end{array}$} \\
\hline & $\begin{array}{l}\text { Crude } \\
\text { OR }\end{array}$ & $95 \% \mathrm{Cl}$ & $\begin{array}{l}\text { Crude } \\
\text { OR }\end{array}$ & $95 \% \mathrm{Cl}$ \\
\hline \multicolumn{5}{|c|}{ Length worked in trade versus $>5$ years } \\
\hline $\begin{array}{l}<1 \text { year } \\
2-5 \text { years }\end{array}$ & $\begin{array}{l}3.11 \\
2.80\end{array}$ & $\begin{array}{l}1.42-6.80 \\
1.39-5.66\end{array}$ & $\begin{array}{l}2.26 \\
1.79\end{array}$ & $\begin{array}{l}0.69-7.39 \\
0.63-5.14\end{array}$ \\
\hline $\begin{array}{l}\text { Percent apprentice, per } \\
10 \% \text { increase }\end{array}$ & 1.12 & $1.02-1.23$ & 1.25 & $1.08-1.45$ \\
\hline Number of tasks performed & 1.08 & $1.00-1.16$ & 1.25 & $1.06-1.48$ \\
\hline Safer crew behaviors score & 0.92 & $0.88-0.97$ & 0.90 & $0.83-0.98$ \\
\hline Safer work climate score & 0.92 & $0.86-0.97$ & 0.90 & $1.06-1.48$ \\
\hline $\begin{array}{l}\text { Worked residential construction } \\
\text { past year }\end{array}$ & 2.10 & $1.27-3.48$ & 3.13 & $1.13-8.83$ \\
\hline
\end{tabular}

a Excludes those who fell from a surface other than a ladder.

Table 5. Predictors of all falls from height for residential apprentices surveyed. All variables/scales were entered into the multiple logistic regression models, only significant variables/scales are reported. (OR= odds ratio, $95 \% \mathrm{Cl}=95 \%$ confidence interval, NS not statistically significant at $\mathrm{P} \leq 0.05$ )

\begin{tabular}{|c|c|c|c|c|}
\hline \multirow[t]{2}{*}{ Variables } & \multicolumn{2}{|c|}{$\begin{array}{l}\text { All falls } \\
(\mathrm{N}=815)\end{array}$} & \multicolumn{2}{|c|}{$\begin{array}{l}\text { Ladder falls a } \\
\quad(\mathrm{N}=722)\end{array}$} \\
\hline & $\begin{array}{l}\text { Adjusted } \\
\text { OR }\end{array}$ & $95 \% \mathrm{Cl}$ & $\begin{array}{l}\text { Adjusted } \\
\text { OR }\end{array}$ & d $95 \% \mathrm{Cl}$ \\
\hline \multicolumn{5}{|c|}{ Length worked in trade versus $>5$ years } \\
\hline $\begin{array}{l}<1 \text { year } \\
2-5 \text { years }\end{array}$ & $\begin{array}{l}3.50 \\
2.43\end{array}$ & $\begin{array}{l}1.54-7.95 \\
1.18-4.50\end{array}$ & $\begin{array}{l}4.75 \\
1.85\end{array}$ & $\begin{array}{c}1.33-16.95 \\
0.63-5.42\end{array}$ \\
\hline $\begin{array}{l}\text { Percent apprentice, per } \\
10 \% \text { increase }\end{array}$ & 1.13 & $1.02-1.24$ & 1.27 & $1.08-1.49$ \\
\hline Number of tasks performed & NS & $\cdot$ & 1.52 & $1.16-1.98$ \\
\hline Safer crew behaviors score & 0.91 & $0.86-0.96$ & 0.91 & $0.83-0.99$ \\
\hline
\end{tabular}

a Excludes those who fell from a surface other than a ladder. 
included both school-based and on-the-job training, apprentices performed tasks on the job prior to training, and many lacked essential fall-prevention knowledge, suggesting that the timing and content of carpenter apprenticeship training could be improved.

Ladders accounted for most of the falls in our sample, which is similar to findings of previously published studies (21-23). Worker training prior to ladder use on the job was rare. Apprentices reported unsafe ladder climbing behaviors by other crew members, which was confirmed by worksite observations at sites employing these apprentices where extension ladders were secured only $22 \%$ of the time and step ladders were used inappropriately at $49 \%$ of the sites audited (24). Our finding of the apprentices' perceived low risk of falling from ladders is an example of inexperienced workers mistakenly perceiving that routinely used equipment does not require special knowledge or skills (25). The low rates of ladder training suggest that contractors and apprenticeship trainers may also underestimate these risks.

Our results confirm that carpenters working in residential construction and apprentices with $<1$ year of experience are at greater risk of falling from heights. Apprentices on work crews characterized by a high number of apprentices are also more likely to fall from heights, suggesting that adequate on the job mentorship is essential. Apprentices working on crews that practice safe behaviors when working at heights are less likely to fall than those working with unsafe crew members, stressing the role of safe peer behavior in fall prevention.

This study had a number of strengths and limitations. We used surveillance data, fall prevention safety standards, previous instruments, and subject matter expert feedback to improve the content and construct the validity of our survey, while the scales demonstrated reasonable reliability. We surveyed $43 \%$ of the total apprentice population in our region and had very high response rates, suggesting that the internal and external validity of this work were good. The majority of our sample worked in residential construction, which gave us the opportunity to identify the fall-prevention needs of this high-risk, but infrequently studied, worker population. Although we used self-report to measure crew behaviors, results from this survey closely parallelled behaviors which we observed during the same time interval when auditing residential worksites (24). This study was not able to examine the conditions at the worksite at the time of the fall; however, Lipscomb and colleagues (5) found that fall protection strategies were not in place when they visited worksites soon after falls from heights. Although our population of small contractors was too small to detect a difference in falls by contractor size, we did see a trend towards a greater number of falls in smaller-sized contractors, as suggested by Kines (9), and safer crew behaviors in larger-sized contractors. Since this study sur- veyed only union carpenters, most of whom were young, white males, our findings may not be generalized to the non-union environment or older and more experienced carpenters, women, or minorities. Because of the crosssectional design of our study, the survey occurred after the apprentices had fallen, and their responses on the survey may have changed as a result of the fall.

Our findings add to the growing literature on the unacceptably high rate of falls in residential construction. Since falls account for most of the construction worker deaths in residential framing and the highest costs per injury claim (21), interventions to address the personal and organizational factors associated with falls from heights are needed. Our research points to several factors that could improve worker safety at homebuilding sites. Use of the construction methods outlined in the OSHA residential guidelines (7) can decrease worker falls from heights; however, these methods are practiced inconsistently at best. Increasing contractor and carpenter awareness and understanding of the methods described in these guidelines, and increasing the use of available technologies at residential worksites is recommended. Personal fall arrest systems prevent worker falls to lower surfaces, yet they are not widely used during residential framing (24).

Our research echoes findings from other industries that organizational factors and the workplace safety climate influence worker behavior $(26,27)$. Previous work by our team (5) and Lipscomb et al (14) suggested that inexperienced carpenters do not receive the type or amount of mentorship they would like from journeymen on their work crews. Limiting the number of apprentices working at residential construction sites will increase the opportunities for mentorship; however many contractors have increased the number of apprentices on their residential crews in order to remain competitive in the current home building market. In addition, journeymen may underestimate their role in providing supervision and training to inexperienced workers.

It is apparent that there are many opportunities to improve the fall safety of residential carpenters, especially inexperienced workers. Carpenters can assume a more active role in ensuring fall prevention. Apprenticeship training programs can improve the timing and content of fall-prevention training. Contractors can ensure that their work crews are optimally staffed and there is adequate time, training, supervision, and resources to maintain the safety of the workers during all phases of the construction process. Researchers can partner with contractors to improve the safety culture, provide optimal supervision and mentorship, and infuse safe construction methods and technologies into the residential construction process. Policy-makers can increase the levels of enforcement of standards designed to protect workers from falls. 


\section{Acknowledgements}

The authors would like to thank Julia Faucette from University of California at San Francisco, School of Nursing and Marion Gillen from the University of California at Berkeley, School of Nursing for their assistance with data management and analysis and Elena Deych for the statistical analysis. This paper was sponsored by grants from the Center for Disease Control/National Institute of Occupational Safety and Health through the Center for Construction Research and Training (Grant \#U54OH008307) and the National Institutes of Health/National Center for Research Resources through Washington University Institute of Clinical and Translational Sciences (Grant \#1UL1RR024992-01).

\section{References}

1. Bureau of Labor Statistics. National census of fatal occupational injuries in 2007 [Internet]. Washington (DC): Bureau of Labor Statistics, US Department of Labor; 2007 [cited: 28 December 2008]. Available from: http://www.bls. gov/news.release/pdf/cfoi.pdf

2. Bureau of Labor Statistics. Fatal occupational injuries by industry and event or exposure [Internet]. Washington (DC): Bureau of Labor Statistics, US Department of Labor; 2007 [cited 28 December 2008]. Available from: http://www.bls. gov/iif/oshwc/cfoi/cftb0223.pdf

3. Bureau of Labor Statistics. Census of fatal occupational injuries charts, 1992-2006 [Internet]. Washington (DC): Bureau of Labor Statistics, US Department of Labor; 2007 [cited 0 November 2007]. Available from: http://www.bls. gov/iif/oshwc/cfoi/cfch0005.pdf

4. Derr J, Forst L, Chen HY, Conroy L. Fatal falls in the US construction industry. J Occup Environ Med. 2001;43:853-60.

5. Lipscomb HJ, Dement JM, Nolan J, Patterson D, Li L, Cameron W. Falls in residential carpentry and drywall installation: findings from active injury surveillance with union carpenters. J Occup Environ Med. 2003;45:881-90.

6. US Department of Labor, Occupational Safety and Health Administration (OSHA). OSHA Construction Standards: code of federal regulations, title 29, part 1926. 2006 ed. Washington (DC): US Department of Labor, Occupational Safety and Health Administration (OSHA); 2006.

7. US Department of Labor, Occupational Safety and Health Administration (OSHA). Plain language revision of OSHA Instruction STD 3.1, interim fall protection compliance guidelines for residential construction. Washington (DC): US Department of Labor, Occupational Safety and Health Administration (OSHA); 1999. OSHA Directives, STD 3-.1A.

8. National Institute for Occupational Safety and Health
(NIOSH). Worker deaths by falls: a summary of surveillance findings and investigative case reports. Cincinnati $(\mathrm{OH})$ : NIOSH; 2000. Publication 116.

9. Kines P, Mikkelsen K. The effects of firm size on reporting of elevation fall injury in construction trades. J Occup Environ Med. 2003;45(10):1074-8.

10. Neal A, Griffin M, Hart P. The impact of organizational climate on safety climate and individual behavior. Safety Sci. 2000;34:99-109.

11. Chao EL, Henshaw EL. Stairways and ladders: a guide to OSHA Rules: OSHA 3124 (2003 revised). Washington (DC): US Department of Labor, Occupational Safety and Health Administration (OSHA); 2003.

12. US Department of Labor, Occupational Safety and Health Administration. A guide to scaffold use in the construction industry: OSHA 3150 (2002 revised). Washington (DC): US Department of Labor, Occupational Safety and Health Administration (OSHA); 2002.

13. Hermann AM, Jeffress CM. Fall Protection in Construction OSHA 3146. (1998 revised). Washington (DC): US Department of Labor, Occupational Safety and Health Administration (OSHA); 1998.

14. Lipscomb H, Dale A, Kaskutas V, Sherman-Voellinger R, Evanoff B. Challenges in residential fall prevention: insight from apprentice carpenters. Am J Ind Med. 2008;51:60-8.

15. Sokas R, Simmens S, Sophar K, Welch L, Liziewski T. Lead levels in Maryland construction workers. Am J Indl Med. 1996;31:188-94.

16. Rosecrance JC, Cook TM, Zimmermann CL. Work-related musculoskeletal symptoms among construction workers in the pipe trades. Work. 1996;7:13-20.

17. Franks J, Stephenson M, Merry C, editors. Preventing occupational hearing loss - a practical guide [Internet]. Cincinnati $(\mathrm{OH})$ : US Department of Health and Human Services; 1996 [cited: 28 December 2008]. Available from: http://www.cdc.gov/niosh/docs/96-110/pdfs/96-110.pdf.

18. Lusk S, Kerr M, Kauffman S. Use of hearing protection and perceptions of noise exposure and hearing loss among construction workers. Am Ind Hyg Assoc J. 1998;59:466-70.

19. Jeffe DB, Mutha S, L'Ecuyer PB, Kim LE, Singal RB, Evanoff BA, et al. Healthcare workers' attitudes and compliance with universal precautions: gender, occupation, and specialty differences. Inf Control Hosp Epidemiol.1997;18:710-2.

20. Hale A, Hovden J. Management and culture: the third age of safety: a review of approaches to organizational aspects of safety, health and environment. In: Feye AM, Williamson A, editors. Occupational injury: risk, prevention and intervention. Bristol (PA): Taylor and Francis, Inc; 1998:129-165.

21. Lipscomb H, Leiming L, Dement J. Work-related falls among union carpenters in Washington State before and after the vertical fall arrest standard. Am J Ind Med. 2003;44:157-65.

22. Cattledge GH, Schneiderman A, Stanevich R, Hendricks $\mathrm{S}$, Greenwood J. Nonfatal occupational fall injuries in the West Virginia construction industry. Accid Anal Prev. 1996;28:655-63. 
23. Lipscomb HJ, Leiming L, Dement JM. Falls among union carpenters. Am J Ind Med. 2003;44:148-56.

24. Kaskutas V, Dale A, Nolan J, Patterson D, Lipscomb H, Evanoff B. Fall hazard control observed on residential construction sites. Am J Ind Med. 2009;52:491-9.

25. Kines P. Case studies of occupational falls from heights: cognition and behavior in context. J Safety Res. 2003;34:263-71.
26. Griffin MA, Neal A. Perceptions of safety at work: a framework for linking safety climate to safety performance. $\mathrm{J}$ Occup Health Psychol. 2000;5:347-58.

27. Zohar D. A group-level model of safety climate: testing the effect of group climate on microaccidents in manufacturing jobs. J Appl Psychol. 2000;85:587-96.

Received for publication: 25 February 2009 